\title{
The 70 years of Arquivos de Neuro-Psiquiatria
}

\author{
Os 70 anos de Arquivos de Neuro-Psiquiatria
}

Luís dos Ramos Machado, José Antonio Livramento

he journal Arquivos de Neuro-Psiquiatria will reach its 70 ${ }^{\text {th }}$ anniversary in 2012.

It came into being Oswaldo Lange's idealism and, with firm support from Tolosa and Longo, the first issue of Arquivos de Neuro-Psiquiatria was published in June, 1943. Since then, it has maintained absolute regularity of publication, without any delays, despite the immense difficulties faced by its editors, especially in the early years.

Certain milestones are emblematic of its progress: the international indexations, starting with the National Lending Library of Medicine (NLL) in 1947, and including Medline (1966), ISI (1969), Scopus (1998), and SciELO (1999); the outstanding performance of Antonio Spina França Netto as the editor in chief starting in 1986, when the form and content of the journal were renewed and modernized; the adoption of the peer review system, starting in 1988; the entry into SciELO and the open-access system, starting in 1999; the adoption of the English language for all studies, starting in 2009; and the professionalization of the journal, starting in 2010.

The problems that surround the editing process of Arquivos de Neuro-Psiquiatria in the current editorial world are neither small nor easy to resolve. There is a universal trend for large publishers to absorb small journals; shortage of resources; difficulties in achieving improvements in the impact factor; resistance among many Brazilian researchers against publishing their studies with use, despite the enormous visibility that the journal provides for authors and their manuscripts; obstinate refusal of many Brazilian authors to cite studies published in Arquivos de Neuro-Psiquiatria; sparse institutional support from funding bodies; official policies for stimulating scientific production that end up penalizing Brazilian journals; and many operational difficulties, which are often unexpected.

Nonetheless, we can also count on some major support: researchers who continue to publish with us despite having other opportunities abroad; our Area Supervisors; our Reviewers; our Editorial Board; our International Consultative Board; our Editorial Advisers; the Brazilian Academy of Neurology (Academia Brasileira de Neurologia); SciELO; CNPq/CAPES; our Subscribers; and our Advertisers. Through everyone's dedicated participation, for which we give our hearty thanks, we have gained the nourishment and resources that allow us to continue our endeavors and, especially, to dream of a Brazilian journal with greater international projection.

How should we commemorate the $70^{\text {th }}$ anniversary of this journal? It is very simple: by following the example of the Editors who preceded us, or in other words, by always working harder.

In this regard, the following innovations will be implemented. Arquivos de Neuro-Psiquiatria is going to start to be published every month, starting in 2012. Thus, there will be 12 issues instead of the present 6 ones. We believe that in this manner, the editorial process will gain in quality and speed. We will also adopt the Ahead of Print publication system, thereby ensuring that authors have full visibility for their studies online, as soon as the editorial process has been completed, without the need to wait for formal publication. We are going to insert Arquivos de Neuro-Psiquiatria into iPad; and we will create closer ties with the Brazilian Academy of Neurology through a broader and more encompassing partnership.

We have been able to count on exceptional collaboration, already at the ready and highly qualified, to work hard with us, especially over the last two years, when we started a wide-ranging policy of opening up to lists of new direct collaborators.

We would like very much to hear any criticisms and suggestions from our readers, authors, reviewers, and neuroscience researchers, no matter whether these in relation to modifications to the journal's format, changes to its content, or even changes to strategic aspects of the journal.

We hope that we can continue to reliably count on everyone's participation and support. Arquivos de Neuro-Psiquiatria will certainly be the journal for all Brazilian neurologists and neuroscientists. Larger, visually more attractive, more representative, more modern, and also increasingly cited. 